Bir Toplum Ruh Sağlığı Merkezinde İzlenen Hastaların Klinik ve Sosyodemografik Özellikleri ile Tedavi Yaklașımlarının İncelenmesi

\title{
Musa Şahpolat*
}

DOI: $10.17944 /$ mkutfd.541189

Musa Șahpolat: Uzm. Dr., Kilis Devlet Hastanesi Psikiyatri Kliniği, Kilis

Email: drmsahpolat@hotmail.com

ORCID iD: https://orcid.org/0000-0002-0022-2389

\section{Bildirimler/Acknowledgements}

Yazarlar bu makale ile ilgili herhangi bir çıkar çatıșması bildirmemișlerdir.

The authors declare that they have no conflict of interests regarding content of this article.

Yazarlar bu makale ile ilgili herhangi bir finansal destek bildirmemișlerdir.

The Authors report no financial support regarding content of this article.

$\therefore$ Sorumlu Yazar/Corresponding Author

Geliș/Received: 17.03 .2019

Kabul/Accepted: 20.05.2019

e-ISSN: 2149-3103

Web: http://dergipark.org.tr/mkutfd
Öz

Bir Toplum Ruh Sağlı̆ı Merkezinde Izlenen Hastaların Klinik ve Sosyodemografik Özellikleri ile Tedavi Yaklașımlarının incelenmesi

Amaç: Bu çalışmada amaç bir Toplum Ruh Sağlığı Merkezi'nden hizmet alan hastaların klinik ve sosyodemografik özellikleri ile tedavi yaklașımlarının incelenmesidir.

Metod: Toplum ruh sağlığı merkezinde kayıtlı ve çalıșmaya katılmayı kabul eden toplam 203 hastayla klinisyen yüz yüze görüș̦me yaparak DSM-IV tanı kriterlerine göre hastalara tanı konuldu. Kesitsel tipte olan çalıșmada tüm hastalara sosyodemografik veri formu, bipolar bozukluk grubu hastalarına ise Hamilton Depresyon Derecelendirme ölçeği (HDDÖ) ve Young Mani Derecelendirme ölçeği (YMDÖ), psikotik bozukluk grubu hastalarına ise Pozitif ve Negatif Sendrom ölçeği (PANSS) uygulandı.

Bulgular: Çalıșmamızda 52(\%25,6) hastada bipolar bozukluk tanısı, $151(\% 74,4)$ hastada psikotik bozukluk tanısı var-

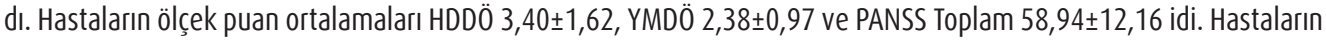
çoğunluğu erkek olup hanedeki ilk ve ikinci çocuklarda ruhsal hastalığın daha fazla oranda görüldüğü belirlenmiștir. $78(\% 38,4)$ hastanın birinci derecede yakınlarında psikiyatrik hastalığın olduğu, bunun yanında $24(\% 11,8)$ hastada adli sorun öyküsünün ve $4(\% 2)$ hastada madde kötüye kullanımı öyküsünün olduğu görülmüștür. Tedaviye bakıldığında hastaların $29(\% 14,3)$ kișisi risperidon uzun etkili enjeksiyon formu, 6 (\%3) kișisi paliperidon palmitat uzun etkili enjeksiyon formu ve $9(\% 4,4)$ kișisi aripiprazol uzun etkili enjeksiyon formu kullanmaktaydı.

Sonuç: Bildiğimiz kadarıyla çalıșmamız Türkiye'de Toplum Ruh Sağlığı Merkezi'nden hizmet alan hastaların klinik ve tedavi özelliklerini inceleyen nadir çalıșmalardan biridir. Bu nedenle çalıșmamızın literatür açısından önemli olduğu düșünmekteyiz.

Anahtar Kelimeler: Bipolar bozukluk, Psikotik bozukluk, Toplum Ruh Sağlğı Hizmetleri

\section{Abstract \\ Investigation Clinical and Sociodemographic Characteristics with Treatment Approaches of Patients Followed in a Community Mental Health Center}

objective: The aim of this study to investigate the clinical and sociodemographic characteristics with treatment approaches of patients who receive service from a Community Mental Health Center.

Method: A total of 203 patients who were registered in the community mental health center and who agreed to participate in the study were diagnosed with DSM- IV diagnostic criteria according to the diagnostic criteria. In the cross-sectional study, applied was for all patients, the sociodemographic data form, the bipolar affective disorder patients group applied to Hamilton Depression Rating Scale (HDRS) and Young Mania Rating Scale (YMRS), Positive and Negative Syndrome Scale (PANSS) was applied to with psychotic disorder patients group.

Results: In our study, 52 (25.6\%) patients were diagnosed with bipolar affective disorder and 151 (74.4\%) psychotic disorder. The average scale scores of the patients was HDRS $3.40 \pm 1.62$, YMRS total was $2.38 \pm 0.97$ and PANSS was $58.94 \pm 12.16$. The majority of the patients were male and determined that the first and second children in the household a higher rate of mental illness.78 (38.4\%) patients had psychiatric illnesses in their relatives, 24 (11.8\%) had a history of forensic problems and $4(2 \%)$ had a history of substance abuse. When the treatment was evaluated 29 (14.3\%) patients had long-acting injection form risperidone, 6 (3\%) paliperidone palmitate long-acting injection form and 9 (4.4\%) long-acting injectable aripiprazole.

Conclusion: To our knowledge, study examined the clinical and treatment characteristics of patients receiving services from the Community Mental Health Center is one of the few studies in Turkey. Therefore, our study is considered to important for literature.

Keywords: Bipolar affective disorder, Psychotic disorder, Community Mental Health Services 


\section{GİRIŞ̧}

Ruh sağlığı hizmetlerini, hastane temelli ve toplum temelli model olarak ikiye ayırmak mümkündür. Gelişmiș ülkelerin neredeyse tamamı 1960'lardan itibaren hastalıktan korunma ve tedavi sonrası iyilik halini sürdürmede yetersiz kaldığı ve yoğun insan hakları ihlallerine sebep olabildiği için hastane temelli modeli terk etmeye başlamışlardır (1). Türkiye'de ise 2006 yılında hazırlanan ulusal ruh sağlığı politikası yönergesine göre toplum temelli modele geçiş tavsiye edilmiş, bir süre sonra ise ülkemizdeki ruh sağlığı politikasında değişikliğe gidilerek hastane temelli modelden toplum temelli modele geçme kararı alınmıştır. Sağlık Bakanlığı tarafından Nisan 2009'da Toplum Ruh Sağlığı Merkezleri (TRSM) açma kararı alınarak projelendirme sürecine başlanmıștır $(1,2)$. TRSM'lerin görevlerini; kendisine bağlı coğrafi bölgedeki ağır ruhsal rahatsızlığı olan hastaların ve ailelerin bilgilendirme, hastanın ayaktan tedavisini ve takibini yapma, grup veya bireysel terapi gibi yöntemleri ile hastanın toplum içinde yaşama becerilerinin artırılmasını hedefleyen, iş-uğraş terapisi, psikoeğitim, rehabilitasyon, psikiyatri klinikleri ile ilişki içinde çalışma ve gerektiğinde mobilize ekiple hastanın yaşadığı yerde takibini yapma şeklinde sıralayabiliriz (2). Bolu'da TRSM'de uyumlandırma çalışmalarına başlanana kadar, ülkemizde ruhsal hastalıklara sahip bireylere yönelik uyumlandırma çalışmaları sadece hastane içinde veya gündüz hastaneleri bünyesinde verilmekteydi(3-5).

Bipolar bozukluk patolojik duyguların ve ilişkili klinik anormalliklerin farklılık gösterebildiği, kronik seyirli, döngüsel hastalık ve iyilik dönemleri ile giden, belirgin yeti yitimi ve psikososyal bozulmaya yol açan bir hastalıktır (6). Bipolar bozukluğa sahip olguların yarısından fazlasında tedaviye rağmen düşük iyileşme oranı ve göreceli olarak yüksek tekrarlama riski bulunmaktadır (6-8). Bipolar bozuklukta sonuçların öngörülebilmesi ile ilgili birçok klinik özellik ele alınmaya başlanmış olup kötü sonuçları öngördüğü öne sürülen klinik özelliklerden bazıları şunlardır: erkek olmak (9), kötü iş durumu $(9,10)$, düşük sosyoekonomik düzey (11), toplam hastalık süresi $(12,13)$, alkol-madde kullanım bozuklukları ek tanısı $(9,14)$ olabileceği belirtilmektedir. Bipolar bozukluğun, hastanın evlilik yaşantısını, mesleki durumunu ve yaşamının istisnasız her yönünü etkileyebileceği, şiddetli ve oldukça kalıcı sorunlara yol açabileceği belirtilmektedir (5). Bu gibi nedenlerden dolayı hastaların düzenli takip ve tedavisinin yapılmasının önemli olduğu belirtilmektedir.

Psikotik bozukluk erken yaşlarda başlayan, yineleyici ve kronik doğası ile sıklığı az olmakla birlikte yaygınlığı fazla olan ciddi bir ruhsal bozukluktur. Zihinsel ve toplumsal yeti yitimine neden olarak aileye ve topluma ciddi yükü olan şizofrenin yaşam boyu yaygınlı̆̆ $\% 0,5-1,6$ olarak ka- bul edilmektedir (15). Psikotik bozukluğun hastalık seyrinde meydana gelen bazı önemli klinik durumlar hastalığın bireye, aileye ve topluma olan yansımaları açısından üzerinde önemle durulması gerekmektedir. Psikozda yașam boyu herhangi bir nedenle adli sorun yaşama oranı \%21 olarak bildirilmektedir (16). Şiddet davranışı riskini artıran nedenler olarak akut dönemler, pozitif belirtiler, tedaviye uyumsuzluk, şiddet öyküsü ve madde kötüye kullanımı sayılabilir (17-19). Bu nedenlerden dolayı psikoz hastalarının düzenli takip ve tedavisinin yapılmasının önemli olduğu belirtilmektedir.

Bu çalıșmada amaç bir Toplum Ruh Sağlığı Merkezi'nden hizmet alan hastaların klinik ve sosyodemografik özellikleri ile tedavi yaklaşımlarının incelenmesidir.

\section{GEREÇ VE YÖNTEM}

\section{Örneklem ve Uygulama}

$\mathrm{Bu}$ çalışma kesitsel tipte bir çalışmadır. Bir Toplum Ruh Sağılığı Merkezinde takip ve tedavi edilen bipolar bozukluk tanısı veya psikotik bozukluk tanısı alan 203 hasta çalışmaya dahil edildi. Çalışmaya TRSM'de kayıtlı ve çalışmaya katılmayı kabul eden hastalar dahil edildi. Çalışma Helsinki Deklerasyonu kararlarına, Hasta Hakları Yönetmeliğine ve etik kurallara uygun olarak planlandı ve çalışma için Etik Kurul onayı yerel Tıbbi Etik Kurulundan alındı. Görüşmeler hastanın yanında bir başkasının olmamasına özen gösterilerek özel görüşme odasında yapıldı. Hastalara ayrıntılı şekilde çalışmanın amacı ve kişisel bilgilerin gizliliğinin korunacağı açıklandı. Çalışmaya katılmayı isteyip istemedikleri soruldu ve gönüllü olanlar çalışmaya alındı. Sosyodemografik veri formu hastalarla birebir görüşülerek klinisyen tarafından dolduruldu. Çalışmaya dahil edilen bipolar bozukluk tanılı hastalara HDDÖ ve YMDÖ ölçekleri, psikotik bozukluk tanılı hastalara ise PANSS ölçeği klinisyen tarafından uygulandı ve tedavi protokolleri ve hastalık özellikleri saptanmaya çalışıldı.

Hastaların sosyodemografik ve klinik özellikleri iki bölümde incelendi. Birinci bölümde sosyodemografik özellikler ilgili bilgiler yer aldı. Hastanın cinsiyeti, eğitim düzeyi, medeni durumu, mesleki yaşamı, ailede psikotik hastalık öyküsü ve hastalığın başlangıç yaşı birinci bölümde incelendi. İkinci bölümde hastalığa ait klinik özellikler incelendi. Hastalığın süresi (ilk psikotik belirtiler ortaya çıktıktan görüşme zamanına kadar geçen süre, yıl olarak), hastalığın gidişi, alkol ve madde kötüye kullanımı, hastalandıktan sonra özkıyım düşüncesi ve girişimi, hastalandıktan sonra adli vaka öyküsü ve tedavi protokolü gibi özellikler ikinci bölümde incelendi. 


\section{Veri Toplama Aracı}

Sosyodemografik Veri Formu: Hastaların yaş, cinsiyet, medeni durumu, öğrenim durumunu, çalışma durumu, ailede ruhsal hastalık varlığı, alkol ve sigara kullanımı, mevcut tedavi şekillerini belirlemek için bu çalışmada kullanılmak üzere geliştirilmiş yarı yapılandırılmış soru formudur.

Hamilton Depresyon Derecelendirme ölçeği-17 (HDDÖ): HDDÖ, depresif belirtileri değerlendirmek için klinik pratikte sıklıkla kullanılan bir ölçektir. HDDÖ, depresif duygudurum, anksiyete, iştah ve uyku değişiklikleri, psikomotor retardasyon veya ajitasyon, cinsel istekte değişiklik, özkıyım düşüncesi, işlevsellikte azalma, somatik belirtiler ve bilişsel belirtileri değerlendiren bir ölçektir. Her sorudaki 0-4 puanlı değerlendirmede psikopatolojinin artan düzeyleri yansıtılmaktadır (20).

Young Mani Derecelendirme ölçeği (YMDÖ): YMDÖ maddeleri, DSM-IV bipolar bozukluk manik dönem ölçütleri ve belirti şiddeti ele alınarak 11 sorudan oluşturulan ve her bir maddenin 0-4 arası puanlandığı bir ölçektir. YMDÖ puanları 0-60 arası değişmekle birlikte, yüksek puanlar maninin şiddeti ile ilişkilidir. Ölçeğin kesme puanı 12 olup klinik olarak iyileşme/ötimik durumu işaret eder $(21,22)$.

Pozitif ve Negatif Belirtiler Ölçeği (PANSS): PANSS, 7 tanesi pozitif belirtileri, 7 tanesi negatif belirtileri ve 16 tanesi ise genel psikopatoloji belirtilerini değerlendiren 30 maddeden oluşan ve yedi puanlı hastalık şiddeti değerlendirmesini içeren yarı yapılandırılmış bir görüşme ölçeğidir (23). Her sorudaki yedi puanlı değerlendirmede psikopatolojinin artan düzeyleri yansitılmaktadır: $1=$ Yok, $2=$ Çok hafif, $3=$ Hafif $4=$ Orta 5= Orta /ağır 6= Ağır 7= Çok Ağır. Kostakoğlu ve arkadaşları (24) tarafından ölçeğin Türkçe güvenirlik ve geçerlik çalışması yapılmıştır.

\section{İstatistiksel Yöntem}

Araştırmada yer alan veriler SPSS Windows 21.0 (Statistical Package for the Social Sciences) paket programı kullanılarak değerlendirildi. Verilerin istatistiksel değerlendirilmesinde tanımlayıcı istatistiksel metodlar (ortalama, standart sapma, frekans) kullanıldı. Normal dağılım gösteren verilerin karşılaştırmalarında Pearson ki-kare testi kullanıldı. Anlamlılık $\mathrm{p}<0.01$ ve $\mathrm{p}<0.05$ düzeylerinde değerlendirildi.

\section{BULGULAR}

Çalışmamızda $52(\% 25,6)$ hastada bipolar bozukluk tanısı ve $151(\% 74,4)$ hastada psikotik bozukluk tanısı vardı. bipolar bozukluk hastalarının kendi aralarında cinsiyet, yaş dağılımı, medeni durum, kaçıncı çocuk olduğu, alkol ve madde kötüye kullanımı açısından istatistiksel olarak anlamlı fark yoktu ( $>>0.05)$. Aynı șekilde psikotik bozukluk grubu hastaların da kendi aralarında cinsiyet, yaş dağılımı, medeni durumu, alkol ve madde kötüye kullanımı açısından istatistiksel olarak anlamlı fark yoktu $(p>0.05)$. Bipolar bozukluk hastalarında ilköğretim mezunu olmak, hastalığın ilk 10 yılında olmak, hastalık öncesi iş sahibi iken hastalık sonrası işsiz olmak özellikleri istatistiksel olarak anlamlı farklılık vardı $(\mathrm{p}<0.05)$. Psikotik bozukluk hastaların ilköğretim mezunu olmak, ilk çocuk olmak, hastalık öncesi iş sahibi iken hastalık sonrası işsiz olmak ve adli sorun yaşamak açısından istatistiksel olarak anlamlı farklılık vardı ( $\mathrm{p}<0.05)$. Tablo 1'de hastaların sosyodemografik özellikleri gösterilmiştir.

Hastaların \%25.1'i ( $n=51)$ herhangi bir uzun etkili IM antipsikotik kullanmaktaydı. İlaç kullanımı açısından uzun etkili ikinci kuşak antipsikotikler arasından risperidone uzun etkili form IM kullanmı diğerlerine göre daha fazlaydı. Tablo 2'de hastaların uzun etkili IM antipsikotik kullanı$\mathrm{m}$ açısından özellikleri gösterilmiştir.

Hastalara ait klinik ölçek puanları tablo 3'de gösterilmiştir.

\section{TARTIŞMA}

Çalışmamızda $52(\% 25,6)$ hastada bipolar bozukluk tanısı ve $151(\% 74,4)$ hastada psikotik bozukluk tanısı vardı. Ülkemizde yapılan toplum örneklemli kesitsel araştırmalarda yaşam boyu psikotik bozukluk yaygınlığını 1000 kişide 26, şizofreni yaygınlığını 1000 kişide 8, şizoafektif bozukluk yaygınlığını 1000 kişide 2, bipolar bozukluk yaygınlığını 1000 kişide 4 olarak bildirilmiştir (25-27). Şizofreni yaygınlığına göre bipolar bozukluk yaygınlığı genel toplum örneklemli kesitsel araştırmalarda genellikle daha düşük olduğu belirtilmektedir (26). TRSM örnekleminde psikotik bozukluğun daha yaygın olması; bu hastalıklara sahip kişilerin yeti yitiminin bipolar bozukluğa sahip kişilere göre daha şiddetli olması nedeniyle psikotik bozukluğu olan kişilerin daha fazla TRSM'ye başvuruyor olması ile açılanabilir.

Çalışmamızda $119(\% 58,6)$ hasta erkek olup çoğunluğu oluşturmaktadır. Kadınlara göre erkeklerde psikozun genel yaygınlığı daha fazla olup ve tedavi için başvuranlarda erkeklerin daha fazla olduğu bilinmektedir $(25,26)$. Ülkemizde yapılan kesitsel araştırmalarda bipolar bozukluk yaygınlığı kadınlarda daha yüksek olma eğilimindeyken $(26,27)$ farklı ülkelerdeki araştırmalarda erkeklerde daha yüksek olma eğiliminde olduğunu bildiren çalışmalar da bulunmaktadır (28).

Çalışmamızdaki hastaların \%52,2'lik evli olma oranının diğer çalışmalardaki bulgular ile benzer olduğu görülmektedir (29). Örneğin İtalya'da yapılan EMBLEM çalışmasında (30) da bipolar bozukluk hastalarındaki evli olma oranı bizim çalışmamızdaki oran ile hemen hemen aynıdır $(\% 46,3)$. 
Tablo 1. Hastaların sosyodemografik özellikleri

\begin{tabular}{|c|c|c|c|}
\hline Özellikler & $\begin{array}{c}\text { Toplam } \\
(\mathbf{n}=\mathbf{2 0 3}, \% 100)\end{array}$ & $\begin{array}{c}\text { Bipolar bozukluk } \\
\text { grubu } \\
(n=52, \% 25,6)\end{array}$ & $\begin{array}{c}\text { Psikotik bozukluk } \\
\text { grubu } \\
(\mathrm{n}=151, \% 74,4)\end{array}$ \\
\hline \multicolumn{4}{|l|}{ Cinsiyet } \\
\hline Kadın & $84(41,4)$ & $21(40,4)$ & $63(41,7)$ \\
\hline Erkek & $119(58,6)$ & $31(59,6)$ & $88(58,3)$ \\
\hline \multicolumn{4}{|c|}{ Yaş (=44.98 \pm 13.17$)$} \\
\hline $18-27$ & $19(9,4)$ & $4(7,7)$ & $15(9,9)$ \\
\hline $28-37$ & $53(26,1)$ & $18(34,6)$ & $35(23,2)$ \\
\hline $38-47$ & $45(22,2)$ & $14(26,9)$ & $31(20,5)$ \\
\hline $48-57$ & $53(26,1)$ & $9(17,3)$ & $44(29,1)$ \\
\hline $58-67$ & $21(10,3)$ & $5(9,6)$ & $16(10,6)$ \\
\hline 68 ve üstünde & $12(5,9)$ & $2(3,8)$ & $10(6,6)$ \\
\hline \multicolumn{4}{|l|}{ Medeni durum } \\
\hline Bekar & $97(47,8)$ & $20(38,5)$ & $77(51,0)$ \\
\hline Evli & $106(52,2)$ & $32(61,5)$ & $74(49,0)$ \\
\hline \multicolumn{4}{|l|}{ Eğitim düzeyi } \\
\hline Okuryazar değil & $40(19,7)$ & $6(11,5)$ & $34(22,5)$ \\
\hline İlköğretim & $108(53,2)$ & $24(46,2)$ & $84(55,6)$ \\
\hline Lise & $41(20,2)$ & $15(28,8)$ & $26(17,2)$ \\
\hline Yüksekokul & $14(6,9)$ & $7(13,5)$ & $7(4,6)$ \\
\hline \multicolumn{4}{|c|}{ Kaçıncı çocuk olduğu } \\
\hline 1. & $50(24,6)$ & $6(11,5)$ & $44(29,1)$ \\
\hline 2. & $48(23,6)$ & $13(25,0)$ & $35(23,2)$ \\
\hline 3. & $36(17,7)$ & $11(21,2)$ & $25(16,6)$ \\
\hline 4. & $29(14,3)$ & $9(17,3)$ & $20(13,2)$ \\
\hline 5. ve üstü & $40(19,7)$ & $13(25,0)$ & $27(17,9)$ \\
\hline \multicolumn{4}{|c|}{ Hastalık süresi $(=18.54 \pm 11.99)$} \\
\hline $1-10$ yll & $63(31,0)$ & $21(40,4)$ & $42(27,8)$ \\
\hline $11-20$ yll & $68(33,5)$ & $20(38,5)$ & $48(31,8)$ \\
\hline 21 yll ve üstü & $72(35,5)$ & $11(21,2)$ & $61(40,4)$ \\
\hline \multicolumn{4}{|c|}{ Hastalık öncesi iş sahibi olma durumu } \\
\hline Olan & $110(54,2)$ & $37(71,2)$ & $73(48,3)$ \\
\hline Olmayan & $93(45,8)$ & $15(28,8)$ & $78(51,7)$ \\
\hline \multicolumn{4}{|c|}{ Hastalık sonrası iş sahibi olma durumu } \\
\hline Olan & $52(25,6)$ & $20(38,5)$ & $32(21,2)$ \\
\hline Olmayan & $151(74,4)$ & $32(61,5)$ & $119(78,8)$ \\
\hline \multicolumn{4}{|c|}{ Ailede psikiyatrik hastalık öyküsü } \\
\hline Olan & $78(38,4)$ & $27(51,9)$ & $51(33,8)$ \\
\hline Olmayan & $125(61,6)$ & $25(48,1)$ & $100(66,2)$ \\
\hline \multicolumn{4}{|c|}{ Adli sorun yaşama durumu } \\
\hline Yaşayan & $24(11,8)$ & $7(13,5)$ & $17(11,3)$ \\
\hline Yaşamayan & $179(88,2)$ & $45(86,5)$ & $134(88,7)$ \\
\hline \multicolumn{4}{|c|}{ Madde kötüye kullanma durumu } \\
\hline Kullanan & $4(2,0)$ & $2(3,8)$ & $2(1,3)$ \\
\hline Kullanmayan & $199(98,0)$ & $50(96,2)$ & $149(98,7)$ \\
\hline \multicolumn{4}{|c|}{ Alkol kötüye kullanma durumu } \\
\hline Kullanan & $6(3,0)$ & $2(3,8)$ & $4(2,6)$ \\
\hline Kullanmayan & $197(97,0)$ & $50(96,2)$ & $147(97,4)$ \\
\hline
\end{tabular}

Çalıșmamızda bipolar bozukluk hastalarının 27'sinin $(\% 51,9)$ ve psikotik bozukluk hastalarının 51'inin $(\% 33,8)$ birinci dereceden yakınlarında psikiyatrik başka bir hastalık tanısının olduğu saptanmıştır. Bipolar bozukluğa sahip hastaların birinci derece akrabalarında hastalık riski \%3-8'tir (31). Akarsu ve arkadaşlarının çalıșmasında genel olarak bipolar bozukluğa hastaların \%27,2'sinin ailesinde bipolar bozukluk öyküsü olduğu belirtilmiş olup literatürle uyumlu olarak cinsiyetler arasında aile öyküsü açısından fark bulunmadığ nın (33) şizofreni hastalarında yaptıkları çalışmada (n:463) (yakınlık derecesi belirtilmeksizin) şizofreni hastalarının yakınlarında psikotik bozukluk oranını \%26, Tang ve arkadașlarının (34) yaptıkları çalıșmada $(n=542)$ şizofreni hastalarının yakınlarında psikotik bozukluk oranını erkeklerde $\% 11$, kadınlarda \%14 olarak bildirilmektedir.

\begin{tabular}{|c|c|c|c|}
\hline İlaç adı & $\begin{array}{c}\text { Toplam } \\
\text { n (\%) }\end{array}$ & $\begin{array}{l}\text { Kadın } \\
\text { n (\%) }\end{array}$ & $\begin{array}{l}\text { Erkek } \\
\text { n (\%) }\end{array}$ \\
\hline \multicolumn{4}{|c|}{ Risperidone uzun etkili form IM kullanma durumu } \\
\hline Kullanan & $29(14,3)$ & $17(20,2)$ & $12(10,1)$ \\
\hline Kullanmayan & $174(85,7)$ & $67(79,8)$ & $107(89,9)$ \\
\hline \multicolumn{4}{|c|}{ Paliperidone Palmitat uzun etkili IM kullanma durumu } \\
\hline Kullanan & $6(3,0)$ & $0(0,0)$ & $6(5,0)$ \\
\hline Kullanmayan & $197(97,0)$ & $84(100,0)$ & $113(95,0)$ \\
\hline \multicolumn{4}{|c|}{ Aripiprazol Maintane IM kullanma durumu } \\
\hline Kullanan & $9(4,4)$ & $5(6,0)$ & $4(3,4)$ \\
\hline Kullanmayan & $194(95,6)$ & $79(94,0)$ & $115(96,6)$ \\
\hline \multicolumn{4}{|c|}{ Zuklopentiksol depot IM kullanma durumu } \\
\hline Kullanan & $7(3,4)$ & $2(2,4)$ & $5(4,2)$ \\
\hline Kullanmayan & $196(96,6)$ & $82(97,6)$ & $114(95,8)$ \\
\hline
\end{tabular}

Çalışmamızda $24(\% 11,8)$ hastada adli sorun öyküsünün olduğu saptanmıştır. Bizim çalışma bulgularımıza benzer şekilde Yıldız ve arkadaşlarının çalışmasında psikoz hastalarında adli olay öyküsü oranı \%11 olarak bildirilmiştir (35). Ülkemizde yatış öyküsü olan hastalarda yapılan bir çalışmada (36) bu oran \%18 olarak bildirilmiştir. Wallace ve arkadaşlarının çalışmasında bizim çalışmaya göre daha yüksek bildirilen (\%21) adli sorun öyküsü madde kullanımı ile ilişkilendirilmiştir (16). Bu bilgi bizim çalışmamızda daha az saptanan madde kullanımı ile ilişkili olabilecek adli sorun öyküsünü desteklemektedir.

Çalışmamızda 4 (\%2) hastada madde kötüye kullanım öyküsünün olduğu saptanmıştır. Bipolar bozukluğu olan hastalarda genel toplum ile karşılaştırıldığında madde kötüye kullanım oranın daha yüksek olduğu bilinmektedir $(37,38)$. Literatürde bipolar bozukluğu olan hastalarda madde bağımlılığı oranı \%14-60, alkol bağımlılığı oranı ise \%6-69 arasında değișmekte olduğu belirtilmiştir (16,39- 
41). Şizofreni hastalarında sigara en sık kullanılan madde olup içme oranı \%56-88 olarak bildirilmektedir. Şizofrenide diğer madde kötüye kullanımları ise sırasıyla alkol, esrar, amfetamin ve kokain şeklinde bildirilmiştir $(42,43)$. Bu çalışmada bilgiler hastanın ve/veya hasta ile ilgili bilgi veren yakınlarının bildirimine dayanmaktadır. Ülkemizde alkol ve madde kullanımının hoş karşllanmayan bir durum olması, hasta ve yakınlarının ahlaki, dini sebeplerden dolayı tutumları ya da adli bir sorun yaşama endişesi nedeniyle bilgi saklamış olması ihtimali gibi birçok neden olabilir. Bizim çalışmamızdaki oranların daha düşük olmasının nedenlerinin bunlar olabileceğini düşünmekteyiz.

\begin{tabular}{|lcc|}
\hline \multicolumn{2}{|l|}{ Tablo 3. Hastaların ölçek puan dağılımı } & \pm SS \\
\hline Ölçek & $\mathbf{n}(\%)$ & $3,40 \pm 1,62$ \\
HDDÖ & $52(25,6)$ & $58,94 \pm 12,16$ \\
PANSS Toplam & $151(74,4)$ & $2,38 \pm 0,97$ \\
YMDÖ & $52(25,6)$ &
\end{tabular}

Çalışmamızda hastaların tedavilerine bakıldığında; hastaların \%25,1'i ( $n=51)$ herhangi bir uzun etkili IM antipsikotik kullanmaktaydı, \%14,3'ü (n=29) risperidon uzun etkili enjeksiyon formu, \%3'ü $(n=6)$ paliperidon palmitat uzun etkili enjeksiyon formu, \%4,4'ü (n=9) aripiprazol uzun etkili enjeksiyon formu gibi uzun etkili 2. kuşak antipsikotikler kullanmakta olduğu saptanmıştır. Antipsikotik tedaviye uyumsuzluk hastalarda önemli sorunlardan biridir. Antipsikotiklerin kullanımına başlandıktan sonra sonra tedaviye uyumu arttırmak için 1960'lı yıllarda geliştirilen depo antipsikotikler yineleme ve hastaneye yatışı anlamlı olarak azaltmışlardır $(44,45)$. Klasik antipsikotiklere göre atipik antipsikotik ilaçların tedavi uyumunu arttırmada ve yinelemeleri önlemede daha üstün olduğunu ortaya koyan çalışmalar vardır (46-48). Bipolar bozukluk hastalarında İM antipsikotik ilaç kullanımı da bölgeler arasında farklılık göstermektedir. Araştırmalarda İM antipsikotik ilaç kullanımı en çok Ege bölgesinde (\%50) ve en az ise İç Anadolu bölgesinde $(\% 19,1)$ olduğu belirtilmiştir $(48,49)$. Bunun nedeni olarak da, çalışmaya katılan hastaların özellikleri ya da hekimlerin tercihleri ile ilişkili olabileceği belirtilmiştir. Birçok kronik psikotik bozukluğa sahip hastada kullanılan uzun etkili depo antipsikotik enjeksiyonların avantajlarına rağmen, tüm dünyada, ulusal, bölgesel ve yerel farklılıklarla birlikte uzun etkili depo antipsikotik enjeksiyon formu ile tedavi edilenlerin oranı \%15 kadar olduğu bildirilmektedir $(49,50)$. Bizim çalışmamızda hastaların uzun etkili antipsikotik enjeksiyon kullanım oranı \%25,1'dir. Bu oranın farklılığında TRSM'ye başvuran psikotik bozukluk popülasyonun, genel psikotik bozukluk hastalığına sahip popülasyonuna göre daha şiddetli olguları içeriyor olabileceği düşünülebilir.

Çalışmamızın bazı kısıtlılıkları bulunmaktadır. Çalışmanın tek merkezli olarak yapılmış olması bu çalışmanın kısıtlılıklarındandır. Çalışma yapılan bölge ile diğer bölgeler arasında demografik farklılıklar bulunabilir. Bu çalışmadan çıkarımlarımız kesitsel çalışma şeklinin kısitlılıkları ele alınarak değerlendirilmelidir.

Çalışmamızın bazı önemli tarafları da bulunmaktadır. Bildiğimiz kadarıyla, çalışmamız Türkiye'de Toplum Ruh Sağlığı Merkezi'nden hizmet alan hastaların klinik ve tedavi özelliklerini inceleyen nadir çalışmalardan biridir. Çalışmaya alınan hastalar, Toplum Ruh Sağlığı Merkezi gibi bir sağlık kuruluşunda takipli ve düzenli poliklinik izlemlerine uyum gösteren hastalardan oluşmaktadır. Bu nedenle çalışma grubundaki hastaların toplumdaki diğer bipolar bozukluk ve psikotik bozukluk tanılı hastaları kısıtlı da olsa yansıtabileceği düşünülmektedir. Ayrıca bu çalıșmanın hastaların tedavi protokolünü inceleyen bir çalıșma olması da literatür açısından önem arz ettiği düşünülmektedir. $\mathrm{Bu}$ konu ile ilgili benzer bir çalışmanın çok az olması ve sonuçlarının klinik uygulamada yol gösterici özellikte olmasının, bir ön çalışma olarak bu çalışmayı değerli kıldığı kanısındayiz.

\section{KAYNAKLAR}

1. Avrupa için Ruh Sağlı̆̆ı Eylem Planı ve Deklerasyonu. Dünya Sağlık Örgütü. Helsinki; 2005.

2. Alataş G, Karaoğan A, Arslan M, Yanık M. Toplum Temelli Ruh Sağlığı Modeli ve Türkiye'de Toplum Ruh Sağlığı Merkezleri Projesi. Noropsikiatri Arşivi 2009;46:25-9.

3. Yıldız M. Psikiyatrik rehabilitasyon yönelimli gündüz hastanesi uygulaması: Kocaeli Üniversitesi deneyimi. Anadolu Psikiyatri Derg 2008;9(Ek sayı.1):9-13.

4. Doğan O. Şizofreni hastalarının evde bakımı. Anadolu Psikiyatri Derg 2001;2(1):41- 46.

5. Ensari H, Gültekin BK, Karaman D, ve ark. Bolu Toplum Ruh Sağlığı Merkezi hizmetlerinin şizofreni hastalarındaki yaşam kalitesi, yeti yitimi, genel ve sosyal işlevsellik üzerine etkisi: Bir ylllık izleme sonuçları. Anadolu Psikiyatri Derg 2013;14(2):108-114.

6. Doğan O. Psikiyatrik epidemiyoloji ve önemi. O Doğan (Ed.), Psikiyatrik Epidemiyoloji, İzmir: Ege Psikiyatri Yayınları, 2002, s.7-14.

7. Rouget B, Aubry J. Efficacy of psychoeducational approaches on bipolar disorders: a review of the literature. J Affect Disord 2007;98(12):11-27.

8. Otto M, Reilly-Harrington N, Sachs G. Psychoeducational and cognitivebehavioral strategies in the management of bipolar disorder. Journal of Affective Disorders 2003;73(1-2):171-81

9. Tohen M, Walternaux CM, Tsuang MT. Outcome in mania: a 4 year prospective follow-up of 75 patients utilizing survival analysis. Arch Gen Psychiatry 1990;47:1106-1111.

10. Gitlin MJ, Swendsen J, Heller TL ve ark. Relapse and impairment in bipolar disorder. Am J Psychiatry 1995;152:1635-1640. 
11. Kora K, Saylan M, Akkaya C, ve ark. Predictive factors for time to remission and recurrence in patients treated for acute mania: Health outcomes of manic episodes (HOME) study. Prim Care Companion J Clin Psychiatry 2008;10(2):114-9.

12. Özerdem A, Tunca Z, Kaya N. The relatively good prognosis of bipolar disorders in a Turkish bipolar clinic. J Affect Disord 2001;64(1):27-34.

13. Keck PE Jr, Mc Elroy SL, Strakowski SM ve ark. 12- month outcome of patients with bipolar disorder following hospitalization for a manic or mixed episode. Am J Psychiatry 1998;155:645-652.

14. Ünal A, Kuloğlu M, Atmaca M, Geçici Ö, Tezcan E. Bipolar bozukluğa eşlik eden eksen I ve eksen II tanıları. Türkiye`de Psikiyatri 2007;9:1825.

15. Rössler W, Salize HJ, van Os J ve ark. Size of burden of schizophrenia and psychotic disorders. European Neuropsyhopharmacology 2005;15(4):399-409.

16. Wallace C, Mullen PE, Burgess P ve ark. Criminal Offending in SchizophreniaOvera25-YearPeriod Marked byDeinstitutionalization and Increasing Prevalence of Comorbid Substance Use Disorders. Am J Psychiatry 2004;161:716-27.

17. Swanson JW, Swartz MS, Van Dorn RA ve ark. A national study of violent behavior in persons with schizophrenia. Arch Gen Psychiatry 2006;63(5):490-9.

18. Swartz MS, Swanson JW, Hiday VA ve ark. Taking the wrong drugs: the role of substance abuse and medication noncompliance in violence among severely mentally ill individuals. Soc Psychiatry Psychiatr Epidemiol 1998;33(Suppl 1):75-80.

19. Bobes J, Fillat O, Arango C ve ark. Violence among schizophrenia out-patients compliant with medication: prevalence and associated factors. Acta Psychiatr Scand 2009;119(3):218-25.

20. Osher Y, Cloninger CR, Belmaker RH. TPQ in euthymic manic depressive patients. J Psychiatr Res 1996;30:353-7.

21. Karadağ F, Oral T, Aran Yalçın F, Erten E. Young Mani Derecelendirme Ölçeğinin Türkiye'de geçerlik ve güvenilirliği. Türk Psikiyatri Dergisi 2001;13(2):107-14.

22. Keller MB. Prevalence and impact of comorbid anxiety and bipolar disorder. J Clin Psychiatry 2006;1:5-7.

23. Kay SR, Flszbein A, Opfer LA. The positive and negative syndrome scale (PANSS) for schizophrenia. Schizophrenia bulletin 1987;13(2):261.

24. Kostakoğlu AE, Batur S, Tiryaki A, Goğus A. Pozitif ve negatif sendrom ölçeğinin (PANSS) Türkçe uyarlamasının geçerlilik ve güvenilirliği. Turk Psikoloji Dergisi 1999;14(44):23-32.

25. Binbay T, Ulas H, Elbi H ve ark. Türkiye'de Psikoz Epidemiyolojisi: Yaygınlık Tahminleri ve Başvuru Oranları Üzerine Sistematik Bir Gözden Geçirme. Turk Psikiyatri Derg 2011;22:40-52.

26. Binbay $\mathrm{T}$, Alptekin $\mathrm{K}$, Elbi $\mathrm{H}$ ve ark. İzmir Kent Merkezinde Şizofreni ve Psikotik Belirtili Bozuklukların Yaşamboyu Yaygınlığı ve İlişkili Oldukları Sosyodemografik Özellikler. Turk Psikiyatri Derg 2012;23:149-160.
27. Özdemir Ö, Doğan O. Sivas il merkezinde iki uçlu duygudurum bozukluğunun yaygınlığı, psikiyatrik eş tanıları ve hastaların yaşam kalitesi. Anadolu Psikiyatri Derg 2015;16:85-94.

28. Merikangas KR, Jin R, He JP, ve ark. Prevalence and correlates of bipolar spectrum disorder in the world mental health survey initiative. Arch Gen Psychiatry 2011;68:241-251.

29. Karamustafalığlu N, Alpay N, Tomruk B. İki uçlu mizaç bozukluğunda cinsiyet farklılıkları ve tedaviye yansımaları. Anadolu Psikiyatri Derg 2004;5(1):28-36.

30. Bellantuono C, Barraco A, Rossi A, Goetz I. The management of bipolar mania: a national survey of baseline data from the EMBLEM study in Italy. BMC Psychiatry 2007;7:33.

31. Köroğlu E, Güleç C (Ed.). Psikiyatri Temel Kitabı. 2.Baskı. Ankara: HYB Basım Yayın, 2007:273.

32. Akarsu S, Erdem M, Bolu A, Günay H, Garip B, Ak M et al. Bipolar bozuklukta cinsiyete göre klinik ve sosyodemografik özelliklerin karșılaștırılması. Gülhane Tıp Dergisi 2012;54:279-283.

33. Belli H, Özçetin A, Ertem Ü, ve ark. Şizofreni hastalarında bazı sosyodemografik özellikler ve tedavi ile ilişkili etkenler. Anadolu Psikiyatri Dergisi 2007;8(2):102-112.

34. Tang Y, Gillespie CF, Epstein MP ve ark. Gender differences in 542 Chinese inpatients with schizophrenia. Schizophr Res 2007;97(13):88-96.

35. Yıldız M, Yazıcı A, Böke Ö. Şizofrenide Nüfus ve Klinik Özellikler: Çok Merkezli Kesitsel Bir Olgu Kayıt Çalışması. Türk Psikiyatri Dergisi 2010;21(3):213-224.

36. Karşıdağ Ç, Alpay N, Kocabıyık A ve ark. Şizofreni ve sigara bağımlılı̆̆ı. Düşünen Adam: Psikiyatri ve Nörolojik Bilimler Dergisi 2005;18(1):13-20.

37. Brady KT, Lydiard RB. Bipolar affective disorder and substance abuse. J Clin Psychopharmacol 1992;12(Suppl. 1):S17-S22.

38. Regier DA, Farmer ME, Rae DS, et al. Comorbidity of mental disorders with alcohol and other drug abuse. Results from the Epidemiologic Catchment Area (ECA) Study. JAMA 1990;264(19):2511-8.

39. Özyıldırım İ, Yargıç İ, Berkol T. Bir duygudurum bozuklukları biriminde izlenen bipolar bozukluğu olan hastalarda alkol kullanım bozukluğunun sıklığı. Nöropsikiyatri Arşivi 2009;46:140-142.

40. Chengappa NKR, Levine J, Gershon S, Kupfer DJ. Lifetime prevalence of substance or alcohol abuse and dependence among subjects with bipolar I and II disorders in a voluntary registry. Bipolar Disord 2000;2:191-195.

41. Kroon JS, Wohlfarth TD, Dieleman J, Sutterland AL, Storosum JG, Denys D, et al. Incidence rates and risk factors of bipolar disorder in the general population: a population-based cohort study. Bipolar Disord 2013;15:306-313.

42. Karakuş G, Evlice YE, Tamam L. Psikiyatri kliniğinde yatan hastalarda alkol ve madde kullanım bozukluğu sıklığı. Çukurova Üniversitesi Tıp Fakültesi Dergisi, 2012;37:37-48. 
43. Aras Hİ. Şizofrenide alkol madde kullanım bozuklukları eş tanısı. Psikiyatride Güncel Yaklaşımlar Dergisi, 2013;5:260-275.

44. Davis JM, Matalon L, Watanabe MD, Blake L, Matalon L. Depot antipsychotic drugs. Place in therapy. Drugs 1994;47:741-773.

45. Tuglu C. Antipsikotiklerin Bipolar Bozuklukta Kullanımı. Klinik Psikofarmakoloji Bulteni-Bulletin of Clinical Psychopharmacology 2008;18(Suppl.2):S50-S56.

46. Çetin M, Turgay A. Modern Psikofarmakolojinin ellinci yllında klorpromazinden günümüze antipsikotik tedavinin dünü bugünü. Klinik Psikofarmakoloji Bülteni; 2002;12:211-226.

47. Leucht S, Barnes TR, KisslingW, Engel RR, Correll C, Kane JM. Relapse prevention in schizophrenia with new generation antipsychotics. A systematic review and explorative metaanalysis of randomized controlled trials. Am J Psychiatry 2003;160:1209-1222.

48. Uzun O, Doruk A. Bipolar bozuklukta duygudurum duzenleyiciler ve atipik antipsikotikler. Turkiye Klinikleri Dahili Tıp Bilimleri Dergisi Psikiyatri 2006;2:37-45.

49. Akkaya C, Altın M, Kora K ve ark. Türkiye'de Bipolar I Bozukluğu Hastalarının, Sosyodemografik ve Klinik özellikleri-HOME Çalışması. Klinik Psikofarmakoloji Bülteni 2012;22:31-42.

50. Rothbard AB, Kuno E, Roley K. Trends in the rate and type of antipsychotic medications prescribe to persons with schizophrenia. Schizophrenia Bull 2003;29:531-540. 